Tesis. Año 13, 12(15), 2019, 151-172

\title{
Posibilidades de la expresión: los problemas del lenguaje en la obra narrativa de Alejandra Pizarnik
}

\author{
María Guadalupe Torres Zuluaga \\ mtorresz1712@icloud.com
}

\section{Resumen}

El presente artículo describe los problemas del lenguaje manifestados por Alejandra Pizarnik (Argentina, 1936-1972) en su obra escritural hasta llegar al punto álgido de estos: el texto en prosa La bucanera de Pernambuco o Hilda la polígrafa (1972), que resulta trascendente por el estilo singular que rompe los moldes de los escritores contemporáneos a ella en Latinoamérica. La ineficacia del lenguaje para describir a sus designata señalada en este y otros textos será refrendada por los comentarios críticos de algunos de sus estudiosos: Vizcaíno, Piña, Venti, Negroni, entre otros. Afirmamos que La bucanera... es una propuesta de encodificación "caótica" como reacción a la pérdida de poder sufrida por el lenguaje. Esta situación es el hilo conductor de toda la obra pizarnikiana. Palabras clave: narrativa, lenguaje, expresión, Pizarnik, escritura.

\section{Abstract}

The present article describes the language problems manifested by Alejandra Pizarnik (Argentina, 1936-1972) in her literary work until they reach the peak of these: the prose text La bucanera de Pernambuco o Hilda la poligrafa, which is transcendent by her singular style that breaks the molds of contemporary writers to her in Latin America. The inefficiency of the language to describe their designata exposed in this and other texts will be endorsed by the critical comments from some of her scholars: Vizcaíno, Piña, Venti, Negroni, among others. We affirm that La bucanera... is a proposal of "chaotic" encoding as a reaction to the loss of power suffered by language. This situation is the guiding thread of the entire Pizarnikian work.

Key words: narrative, languaje, expression, Pizarnik, writing. 


\section{Posibilidades de la expresión: los problemas del lenguaje en la obra narrativa de Alejandra Pizarnik}

\section{Introducción}

¿Es el lenguaje anterior a la razón? ¿Es superior a la razón? ¿Es el lenguaje cuestionador de la razón? La escritora argentina Alejandra Pizarnik (1936-1972) nos muestra desde todos los géneros literarios que el lenguaje debe constituirse en un elemento que se autodenuncia, puesto que los códigos con que se manifiesta han perdido su capacidad de representar lo que se piensa y se percibe. Por lo tanto, es imperativo que todos se sientan afectados por ese vacío. Con las ideas vertidas por los académicos que han tratado el tema del lenguaje en la obra de Alejandra Pizarnik, hemos pretendido realizar una cronología de lo que este tópico le simbolizaba: un inicio en el mundo escritural con la sensación de que las palabras son - desde una correcta selección- el medio para acceder al mundo, el único refugio. Y cómo, luego, dentro de un fenómeno de circularidad, el lenguaje ineficaz necesita manifestarse a través de escombros para denunciar desde la acción de destruir la relación significado-significante.

E1 método bibliográfico con posterior procesamiento y trascripción de datos nos ha permitido revisar brevemente el estado de la cuestión de los textos pizarnikianos e identificar los principales elementos que los transitan; especialmente, aquellos que signan sus textos no poéticos, como es el caso de Los poseídos entre lilas (1969) y La bucanera de Pernambuco o Hilda la polígrafa (de 1972, pero publicado en 1982).

Por ejemplo, para Santiago Vizcaíno, estudioso de la obra poética pizarnikiana, "Extracción de la piedra de la locura" (1968), "Endechas" y "En esta noche, en este mundo" (1971) — de sus últimas creaciones— son los poemas que condensan bien la temática de la autora y nos guían a su percepción sobre la verdadera representatividad de las palabras (consideramos al último mencionado como su poema manifiesto); señala, asimismo, que este problema percibido por Pizarnik le sucedió a toda la ciencia y el arte en general en la historia de su evolución: se percibió una nueva incapacidad para "decir" tantos cambios y 
novedades. En la poesía, esta pérdida de poder se hizo clara en el XIX con los poetas malditos. Alejandra Pizarnik entra en este grupo de pleno derecho: es una escritora (no solo poeta) de la marginalidad. Escritora y no solo poeta porque en Pizarnik encontramos todo tipo de textos: ensayos, poemas, estampas, teatro, prosa, además de ser una fervorosa diarista.

Cristina Piña, también estudiosa de la obra de nuestra autora y su principal biógrafa, señala que su lenguaje es fragmentario, puesto que Pizarnik ha realizado también notas, estampas o viñetas (en verdad, aún no se sabe qué son) del libro La comtesse sanglante (1962) de Valentine Penrose, la primera obra en prosa de la argentina.

Maria Negroni, estudiosa de la prosa de nuestra autora, principalmente, es quien ha buscado dentro de los "textos de sombra" (La condesa sangrienta, Los poseidos entre lilas y La bucanera de Pernambuco o Hilda la Poligrafa) la comprensión de la totalidad de los textos pizarnikianos: "como si fuese posible rescatar (...) un mundo más veraz, más vivo” (Negroni, 2003, p.11) y señala que en sus poemas, lo indeseado queda afuera, aunque sería mejor señalar que está oculto. En la prosa, el lenguaje es procaz: incomoda, desestabiliza, trasgrede, pues se da la oportunidad de buscar nuevos caminos: experimenta, juega, rompe la cohesión generando estructuras sintácticas que dicen poco o aparentan no decir nada, inventa palabras, etc.

En algún punto, sin embargo, mi lectura se modificó sutilmente. Pensé que los textos 'malditos' se erguían, frente al resto de la obra (...) pero no se le oponían. Más bien eran la prueba contundente del famoso dictum pizarnikiano de que 'cada palabra dice lo que dice y además más y otra cosa'. (ibidem, p. 12)

No se sabe si es, como señala Negroni, una "celebración del fracaso del proyecto irrealizable de la significación” (ibidem, p. 15), pero Pizarnik parece, muchas veces, regodearse en su decisión de manifestar la imposibilidad del lenguaje. Los poseídos entre lilas nos prepara para La bucanera de Pernambuco que será, entonces, un conjunto de trozos de una masacre expresiva: equivale a la destrucción completa del lenguaje (la misma Negroni señala que existen en $\mathrm{Pi}^{-}$ zarnik textos inasimilables). Los estímulos lingüísticos están presentes en todas las obras, especialmente en la prosa; el tema del lenguaje es parte de su texto y es pretexto también: el lenguaje, y también su ausencia.

¿La expresión lingüística ha ido perdiendo sus capacidades o la autora lo considera así debido a la intención de establecer esa escritura-vida del modelo surrealista? Alejandra Pizarnik fue perdiendo su lucidez hacia el final de su vida, pero no perdió su calidad artística; hubo, simplemente, una disconformidad que cambió su temática y la orilló a ser más oscura. De ahí su "obra de 
sombra”: volvió su lenguaje más exótico, su prosa fue incomprensible, señaló cada vez más que el lenguaje era un medio, pero también un obstáculo.

Es evidente que el tema del lenguaje es el que atraviesa toda la obra escritural de Alejandra Pizarnik, y que, pese a que su producción más pública es la poética, manifestó constantemente (en sus diarios) su intención de ser narradora. La bucanera de Pernambuco ${ }^{1}$, no es precisamente un buen intento, pero es la denuncia en práctica de las ausencias a las que estamos sometidos por la situación en la que se encuentra el lenguaje y, por ello, es el texto central de este artículo; también porque es el segundo texto prosístico (aunque su estructura abunde en voces - diálogos-), pero el primero en ser enteramente pizarnikiano ( $L$ a condesa sangrienta es una versión pizarnikiana del libro de la surrealista francesa Valentine Penrose). Existe un problema con el lenguaje, pero, paradójicamente, este no puede dejar de emplearse: el caos es absoluto ahora.

En la Edad Media, pese al soberano poder de la Iglesia, la magia se practicaba en determinados espacios, en ciertos círculos secretos; existían rituales, amuletos, conjuros en los cuales la relación entre la palabra y el objeto era determinante: "decir la cosa" era sinónimo de "capturarla" o, al menos, "acercarla". Incluso, desde la época clásica griega, había reflexiones críticas del lenguaje que le daban un lugar privilegiado entre las facultades del ser humano; en otras palabras, la relación entre la palabra y el objeto proviene de tiempos remotos, y es que prácticamente todas las esferas de la interacción humana con sus pares y con el medio que lo rodea se dan a través del lenguaje (o de su ausencia), y este es el problema que, consideramos, se volvió el hilo conductor de la obra de la escritora argentina Alejandra Pizarnik, conocida en general como poeta, pero quien nos legó diarios, ensayos, prosa y hasta una obra teatral; lo que la hace una de las voces femeninas hispanoamericanas más representativas del siglo XX, aunque no es un asunto de cantidad, sino de la calidad de su trabajo aquello que lo confirma.

El problema del lenguaje surge con las relaciones entre los primeros hombres que poblaron el mundo, pero, para nuestro propósito, conviene abarcarlo desde la Modernidad. Señala Santiago Vizcaíno en su ensayo Decir el silencio (2008) que este problema se manifiesta, en la lírica moderna, desde Rimbaud. Justamente, el movimiento surrealista al que Pizarnik se adscribía (como lo señaló en una entrevista realizada por Martha Isabel $\mathrm{Moia}^{2}$, clave para entender la obra pizarnikiana) es consecuencia de que la relación entre el lenguaje y el mundo simplemente no exista o haya quedado anulada. ${ }^{3}$

En Manifiestos del surrealismo, de André Bretón, aparecen varias actitudes literarias que nos remiten a la obra pizarnikiana en conjunto. Nos parece apro- 
piado señalarlas brevemente para que se tenga consideración sobre un precedente que eleva a nuestra escritora a la categoría artística que le corresponde, y que le ha sido negada por mucho tiempo: en primer lugar, la prescindencia de la moral. En Manifiestos..., se señala que la forma de dirigirse hacia el estado de ausencia de reglas es la mirada hacia la infancia, en la que se desconoce toda norma. Uno de los tópicos de la argentina es precisamente la infancia; Moia le señala a nuestra autora que los términos como infancia, el silencio, los miedos o la noche son sus "signos y emblemas", y, pese a que la entrevista versa íntegramente sobre su poesía, es claro que en la obra escritural de Pizarnik existe un desarrollo cronológico sobre la pérdida del poder de la palabra "no quiero hablar del jardín: quiero verlo” (Pizarnik, 2014, p. 312); es decir, es más importante la acción que la palabra ${ }^{4}$, pero como su "oficio es conjurar y exorcizar", Pizarnik acepta que para ella son las palabras el medio para acercarse a la acción.

Entre otras cosas escribo para que no suceda lo que temo; para que lo que me hiere no sea; para alejar al Malo (...). Se ha dicho que el poeta es el gran terapeuta. En este sentido el quehacer poético implicaría exorcizar, conjurar y, además, reparar. Escribir un poema es reparar la herida fundamental, la desgarradura. Porque todos estamos heridos. (Becciu Ed., 2014, p. 312)

En Manifiestos... también se pone de relieve la imaginación, pero esta vendría a ser, por exceso, la causante de la locura. Se explica esto en que el "loco" es un ser indiferente a la crítica, puesto que su imaginación le da gran consuelo. Por ello, es inocente. Esto nos lleva a ligar inocencia y locura, pero como la inocencia es característica de la infancia y la locura es más bien un rasgo que se asocia al mundo adulto, la obra pizarnikiana nos confronta con el hecho de asimilar la temática infantil mientras se nos habla del cuerpo o del sexo. Esto puede resultar desagradable para algunas personas, o más que desagradable, deberíamos decir obsceno. Cristina Piña, quien es la investigadora que funda este ciclo y es la biógrafa más importante de Alejandra Pizarnik, nos advierte que, pese al lugar común que es el "mito Alejandra Pizarnik" — ya que es una poeta arquetípica por sus experiencias límite - , hay una relación indesligable de su creación con lo siniestro, lo fatal, lo irrepresentable o lo fuera de escena; en otras palabras, lo obsceno (es un dictum mallarmeano que el silencio enmascara lo obsceno). Para Piña lo obsceno en Pizarnik se manifiesta en su prosa y se enmascara en sus versos, como veremos más adelante; dice esto porque se han subvertido los códigos de lo institucionalizado a nivel literario; por ejemplo, los géneros.

Pero regresando a los tópicos de nuestra escritora argentina; en su caso, el niño - diremos mejor, la niña - es un pequeño loco que habla con su muñeca todo el tiempo. Pero sabemos que no es el plano puramente lógico el que favorece al acto creativo. Breton señala: 
Todavía vivimos bajo el imperio de la lógica, y precisamente a eso quería llegar. Sin embargo, en nuestros días, los procedimientos lógicos tan solo se aplican a la resolución de problemas de interés secundario (...). Al parecer, tan solo al azar se debe que recientemente se haya descubierto una parte del mundo intelectual, que, a mi juicio, es, con mucho, la más importante y que se pretendía relegar al olvido (...). Quizá haya llegado el momento en que la imaginación esté próxima a volver a ejercer los derechos que le corresponden. (Bretón, 2006, p. 20)

Durante mucho tiempo se ha desechado la experiencia y se ha propulsado la razón, pero el hacer también tiene su razón. ¿Por qué debería quitársele importancia al azar y los presentimientos si son fuente de ciencia, $y$, sobre todo, de creatividad? Breton explica esto por medio del sueño: "El hombre, al despertar, tiene la falsa idea de reemprender algo que vale la pena" (ibídem, p. 21). El sueño y, por ende, la noche, pese a esto, han quedado en el plano de las irrelevancias. Al ser "la noche" un tópico de Pizarnik, vemos, dentro de su obra poética, la intención de ir en contra de lo establecido y mostrar su, por ella citado, "surrealismo innato", pero con ciertas reservas iniciales, como veremos más adelante. Primero consideraremos una similitud más, la más importante respecto de esta comparación: el lenguaje.

En el "Primer manifiesto surrealista", Breton critica el estilo "puramente informativo" de las obras modernas; señala que no dejan nada a la imaginación. Lleno de tedio expresa que es una pérdida de tiempo convertir momentos nulos en situaciones. Critica el lenguaje descriptivo de novelas que lo obligan a abandonarlas desde la primera página y culpa al periodismo y a la escasa ambición de los autores de esta insuficiencia en la que no hay ninguna sensación que se desprenda de la obra, ningún sentimiento emanado por el autor, que, por supuesto, produce el mismo efecto en el receptor. A pesar de esto - y aquí debemos reconocer que el surrealismo pizarnikiano es muy particular-, Pizarnik añoraba escribir una obra en prosa que tuviera como modelo la Aurélia (1942), de Nerval.

La autora señala que mediante la escritura de la noche se une a la noche, con lo que confirma que la palabra es un medio y que si antes ha hablado del silencio lo ha hecho de forma ideal, pues no cree que el silencio sea algo posible: "siento que el inagotable murmullo nunca cesa de manar" (Becciu Ed., 2014, p. 313). Asimismo, acepta que el lenguaje es errante; esa "vocación de errancia" de Pizarnik es una condición de vida: de familia rusa, nacida en Argentina, judía y radicada por cuatro años en Francia, como buscando un "cambio de aire", son condiciones que nos muestran la falta o la búsqueda de una patria, o el miedo de no tenerla, a lo que Pizarnik responde que como poeta le corresponde vivir en la palabra: “...me oculto del lenguaje dentro del lenguaje” (id.). Las palabras configuran para la poeta un mundo menos hostil, pero de forma superficial, sin 
esencialidades. El producto de estas sensaciones o forma de vida es el advenimiento de la complejización de su lenguaje, como ya fue mencionado, lo que se siente en libertad de hacer con su prosa, pero no demasiado con sus versos. Muy por el contrario de lo que afirma: “...busco que el poema se escriba como quiera escribirse” (id.) seguimos viendo 'corrección' en sus poemas. Notamos en ellos pulcritud, precisión y economía, sin tocar (en un principio) el tópico de la anulación del lenguaje. Moia le atribuye el "no saber nombrar" (id.) a un afán por encontrarse con su propio lenguaje; Pizarnik señala que esto le produce tensión ${ }^{6}$, y ambas concluyen que ha sido Los trabajos y las noches (1965) en que se ha logrado. En este libro, se encuentra su "ideal de poema realizado".

Santiago Vizcaíno nos aproxima al tema del lenguaje en Pizarnik desde el silencio. Inicia su ensayo Decir el silencio (2008) explicándonos que luego del surgimiento del lenguaje y del intento de ordenarse las relaciones humanas mediante el mismo aparece un supraorden, que quiere llevar los conocimientos a símbolos y modelos que inician la ruptura de la lengua en sí como vehículo, y, además, otras manifestaciones artísticas comienzan a comunicar sensaciones prescindiendo del lenguaje (pintura, escultura, música, etc.): "El lenguaje ya no puede traducir a sus términos el idioma del arte abstracto y no figurativo, puesto que su sensibilidad es anterior al lenguaje, lo rebasa" (Vizcaíno, 2008, p.19). Siendo así, todos los narradores de los que habla Breton tendrían que dejar de crear: no solo su achatamiento como artistas, sino el lenguaje que emplean, destruye el arte. Pizarnik vendrá a constituirse en la versión contemporánea de los escritores que crearon formas que evidenciaban esta "conciencia de crisis": los surrealistas, ya señalados. Las obras con lenguaje tradicional han aplanado su grandiosidad y riqueza, de allí que se dedicaran a rebelarse contra esta forma de concebirlo, como un objeto aislado, como si no fuera parte también de nuestro inconsciente.

En el caso de Rimbaud — dice Vizcaino- hay una preferencia por el silencio que da paso a la acción; en Pizarnik, no. Señalar la renuncia es la manifestación de su rebeldía y expresar el debilitamiento de la palabra, en cada momento, es dar la cara al problema, asumir que existe, y asumir, sobre todo, que no hay una solución viable. Pizarnik habla del silencio, para lo cual, paradójicamente, no puede callar. Se nos muestra a la autora siendo tentada por el silencio, acariciando el silencio como un ideal: "Pizarnik, como Kafka, encontró la manera de expresar (...) una suerte de 'articulación del silencio"” (ibídem, p. 21)7. Y es que, en verdad, existe un problema del lenguaje que el silencio tampoco soluciona: en un juicio (crítico) o selección se pretende ser preciso y el silencio no es un elemento que contribuya con estas situaciones cotidianas, como vemos en "Dificultades barrocas", texto de la parte I de Prosa completa (2014) "Relatos":

Hay palabras que ciertos días no puedo pronunciar (...) ¡Ah esos días en que mi lenguaje es barroco y empleo frases interminables para suge- 
rir palabras que se niegan a ser dichas por mí! (...). Una vez me acosté con un pintor italiano porque no puede decirle 'A mo a esta persona'. En cambio, respondí a sus pedidos con una vaga serie de imágenes recargadas y ambiguas y es así como terminamos en la cama sólo [sic ] porque no pude decir la frase que pensaba. (Becciu Ed., 2014, p. 63)

Vizcaíno señala que hasta Los trabajos y las noches (1965), Pizarnik manifiesta en su escritura una esperanza en el lenguaje; este es aún un vehículo, tal vez no eficiente, pero sí pertinente de comunicación. Es a partir de Extracción de la piedra de la locura (1968) que Pizarnik vuelca su temática y se enfoca en la "problemática de la escritura": es el constante uso del lenguaje el que le ha hecho perder su brillo. La pretensión de Pizarnik es elevar al lenguaje mediante él mismo. Estamos asistiendo en cada lectura y relectura de la argentina a la búsqueda de un lenguaje totalizador ${ }^{8}$ : nos dice Vizcaíno que el silencio pizarnikiano no es un silencio mudo ni un silencio místico, sino un silencio invocador, ya que "El lenguaje es a la vez esencia y obstáculo de la concreción del poema, y el metalenguaje de ese fracaso" (Vizcaíno, 2008, p. 37). Señala, asimismo, que la brevedad de los primeros poemas (La tierra más ajena), a modo de "gritos", es una forma tímida de acercarse a este silencio del que todavía no dice nada (gritos que luego veremos traducirse en el modo de expresión de Erzebeth Bathory, la condesa sangrienta). Pizarnik nos preparaba para el poemario en el que el problema del lenguaje tiene primacía: "Por eso cada palabra dice lo que dice y además más y otra cosa" ("La palabra que sana”, en El infierno musical de 1971, de la edición de Lumen del 2011, p. 283). En cada poemario de Pizarnik, nos vamos acercando más al descubrimiento de su propósito fundamental, el que probablemente ni ella misma conocía cuando aparecieron sus primeros poemas: el problema del lenguaje le causaba una preocupación inconsciente que, al alcanzar el estatus de poetisa, emergió, y nos la enrostró, como una pregunta lanzada con vehemencia hacia la noche cerrada de nuestra ignorancia. Ya en Extracción... el tema del lenguaje ha alcanzado un rango insoslayable: "es el centro generador de su poética” (Vizcaíno, 2008, p. 48). Los espacios anteriores: muerte, infancia, noche, silencio, jardín o bosque, han sido simplemente caminos largos para llegar al puerto de la expresión poética de Pizarnik: el lenguaje ideal (consideremos que Vizcaíno alude específicamente a la obra lírica de la autora argentina).

¿Por qué postergar tanto el tratar abiertamente el tema del lenguaje? Es tal vez acaso una expresión de temor ante la imposibilidad de que otros comprendan esa búsqueda infructuosa de, como ella misma señala, "palabras simples", pero también "palabras buenas" y "palabras seguras". Parece que es solo en el sueño, el campo de las infinitas posibilidades (de todas las posibilidades), en que existe la leve sensación de 'lograr decir' o, mejor señalado por Breton: “El espíritu del hombre que sueña queda plenamente satisfecho con lo que sueña. 
La angustiante incógnita de la posibilidad deja de formularse (...) Todo es de una facilidad preciosa" (Bretón, 2006, pp. 22-23).

En el sueño el rey moría de amor por mí. Aquí, pequeña mendiga, te inmunizan. (Y aún tienes cara de niña; varios años más y no les caerás en gracia ni a los perros) (...). El sueño demasiado tarde, los caballos blancos demasiado tarde. La melodía pulsaba mi corazón y yo lloré la pérdida de mi único bien, alguien me vio llorando en el sueño y yo expliqué (dentro de lo posible), mediante palabras simples (dentro de lo posible), palabras buenas y seguras (dentro de lo posible). (Becciu Ed., 2011, p. 252)

No es esta facilidad la que conduce nuestro mundo, el mundo real. Pizarnik regresó de París con muchas ideas y sensaciones nuevas, como esta de que el mundo en el que "le toca vivir" es aquel en que se usa el lenguaje para comunicar lo banal, lo cotidiano, el que no posee vacíos interpretativos, pero lo frustrante es que los textos literarios (también compuestos de estructuras del lenguaje cotidiano) "(no) dicen lo que me parece oír en ellos” (Moure, 2009, p. 144).

Es El infierno musical (1971) el punto álgido de su creación poética sobre el lenguaje. Ya en su obra en prosa, vamos a poder asimilar el resultado de las dudas y preguntas continuas de su obra poética. ¿Cuál es el resultado de que el lenguaje no sea suficiente más que para la comunicación cotidiana?: su destrucción. ${ }^{9}$ Pizarnik, en su último poemario nos dice, y por última vez de forma sutil, que el lenguaje es un vehículo incompleto, pero sus poemas solo fueron la inauguración de su nuevo lenguaje: "el lenguaje desatado", lo que quiere decir caos, lo que quiere decir sinsentido, lo que quiere decir palabras combinadas que parecen juegos, lo que quiere decir que el lenguaje es un elemento tan oscuro como para hablar desde esa misma oscuridad sobre algo tan insondable como la muerte.

Para concluir esta cronología sobre su obra poética diremos que, poco antes de su muerte, en un poema dedicado a Martha Isabel Moia (aquel que hemos llamado su "poema manifiesto") nos dejó las claves para comprender su poética: admite que es consciente de que el poema se escribe solo, pero dice más: subrepticiamente nos dice que no es que hayan dejado de preocuparle los temas de siempre, los que son inmanentes a su obra, sino que ahora es cuando los está dejando fluir. El miedo a la incomprensión ha salido de la escena; hay ahora una actitud interior y exterior de "poder decir".

en esta noche en este mundo

las palabras del sueño de la infancia de la muerte

nunca es eso lo que uno quiere decir

la lengua natal castra

la lengua es un órgano de conocimiento 
del fracaso de todo poema castrado por su propia lengua que es el órgano de la re-creación del re-conocimiento pero no el de la re-surrección de algo a modo de negación de mi horizonte de maldoror con su perro y nada es promesa entre lo decible que equivale a mentir (todo lo que se puede decir es mentira) el resto es silencio sólo que el silencio no existe

no

las palabras

no hacen el amor

hacen la ausencia si digo agua ¿beberé? si digo pan ¿comeré?

en esta noche en este mundo extraordinario silencio el de esta noche lo que pasa con el alma es que no se ve lo que pasa con la mente es que no se ve lo que pasa con el espíritu es que no se ve ¿de dónde viene esta conspiración de invisibilidades? ninguna palabra es visible

sombras

recintos viscosos donde se oculta

la piedra de la locura

corredores negros

los he recorrido todos

¡oh quédate un poco más entre nosotros!

mi persona está herida

mi primera persona del singular

escribo como quien con un cuchillo alzado en la oscuridad escribo como estoy diciendo

la sinceridad absoluta continuaría siendo

lo imposible

¡oh quédate un poco más entre nosotros!

los deterioros de las palabras deshabitando el palacio del lenguaje

el conocimiento entre las piernas 
¿qué hiciste del don del sexo?

oh mis muertos

me los comí me atraganté

no puedo más de no poder más

palabras embozadas

todo se desliza

hacia la negra licuefacción

y el perro de maldoror

en esta noche en este mundo

donde todo es posible

salvo

el poema

hablo

sabiendo que no se trata de eso

siempre no se trata de eso

oh ayúdame a escribir el poema más prescindible

el que no sirva ni para

ser inservible

ayúdame a escribir palabras

en esta noche en este mundo (Becciu Ed., 2011, pp. 398-400) ${ }^{10}$

Versos como "la lengua es un órgano de conocimiento / del fracaso de todo poema", "y nada es promesa / entre lo decible / que equivale a mentir / (todo lo que se puede decir es mentira)", "si digo agua ¿¿beberé? / si digo pan ¿comeré?", "los deterioros de las palabras / deshabitando el palacio del lenguaje" y "hablo / sabiendo que no se trata de eso / siempre no se trata de eso" manifiestan, nunca de forma más exacta, el no acceso al lenguaje o la pérdida de poder del mismo. La angustia manifestada por la autora se extiende hacia nosotros, que somos usuarios del lenguaje, como si nunca hubiera sido un esfuerzo del hombre, como si fuera un derecho de cada ser que puebla la tierra, que no lo es. Las ruinas del lenguaje nos afectarían tanto como a Pizarnik si las percibiéramos, pero nuestro lenguaje es corriente, es el de todos los días; es nuestra autora la que da cuenta de que deberíamos ser conscientes de que el lenguaje no sirve para expresar lo sublime, pues se ha disuelto en el tiempo.

El gran debate entre académicos que conocen la obra entera de Pizarnik tiene que ver con una situación del lenguaje también: las acusaciones de plagio a las que se ha visto sometida; sin embargo, (señala María Negroni) es, más bien, un caso de intertextualidad: ante las imposibilidades del lenguaje, Pizarnik se atreve a "mejorar a sus autores favoritos": no calca los textos, sino que los reinterpreta y reescribe. Así fue como construyó La condesa sangrienta (1965), su primera obra en prosa, tomando extractos del libro de Valentine Penrose, 
Le comtesse sanglante (1962), y eliminando sus partes serviles (Negroni, 2003, p.85), lo que produjo un texto de naturaleza inclasificable; ${ }^{11}$ asimismo, vamos a encontrar intertexto entre sus propias producciones: de sus poemas a $L a$ condesa..., de Los poseidos entre lilas $(1972)^{12}$ a La bucanera de Pernambuco o Hilda la Poligrafa $(1982)^{13}$.

Parte del mejoramiento señalado, se ve en La condesa sangrienta, texto en el que confluyen todos los "tópicos de la literatura gótica tradicional" (Fuentes, 2007, p. 16): el viejo castillo o monasterio (el castillo de Csejthe), la atmósfera de misterio (rituales mágicos, torturas, sangre), la profecía ancestral (la locura de la sangre Báthory debido a las uniones incestuosas), los eventos de difícil explicación (la desaparición de tantas jóvenes sin que nadie informe a las autoridades), las emociones desbocadas (migrañas de la condesa, sus fuertes accesos de ira y las imprevistas crisis de posesión que le sobrevenían), el erotismo larvado (aparente homosexualidad de Erzébet) y la heroína oprimida (que en este caso es una antiheroína que vive en un mundo absolutamente feminizado, viuda a temprana edad y en compañía de horrendas sirvientas). Esto, suponemos, fue lo que capturó la fina curiosidad de Pizarnik y la hizo afirmar que le hubiera gustado tomar apuntes del método con que lo elaboró, puesto que es el tipo de literatura que quería producir.

Texto fundamental en la obra de sombra de Alejandra Pizarnik, La condesa sangrienta es también, sobre todo, una reflexión alucinatoria sobre el acto de escribir. ¿No podrían verse las muchachas como alegorías de ese mundo que se sustrae para siempre a las palabras y a los poemas como resumen de la cacería infernal o desesperada que acontece en los lavaderos? ¿ ¿No será la cripta, que atesora el cadáver de la primera joven, un espacio equivalente a un aguantadero, un baldío lleno de textos-escombros a robar? ¿Y el castillo mismo una máquina depredadora que anticipa La bucanera de Pernambuco y hace del lector un cómplice en la función delictiva? (Negroni, 2003, p. 29)

Es decir, María Negroni compara el castillo y la acción dentro del castillo con el acto de escritura de nuestra autora. Nos dice que La condesa... inaugura "la noche marginal de su infortunio [del lenguaje]" (ídem); es decir, con este texto comienza a diluirse lo que en los poemas había quedado pendiente: existe un problema con el lenguaje, pero este no tiene solución: "La condesa sangrienta, en este sentido, representa el comienzo del fin". (ibídem, p. 31). Es la primera vez que en Pizarnik publica prosa creativa y, asimismo, es la primera vez que veremos textos-viñeta en nuestra autora, pero no será la última.

Nos muestra el representativo papel de la melancolía a lo largo de la obra de la argentina y la relaciona con el lenguaje en una doble negación (señalada por Julia Kristeva): el aceptar perder algo implica la capacidad de poder recobrarlo 
en el acto del lenguaje, pero en el poeta no se cumple esto, ya que se niega la pérdida, lo que genera un luto eterno; en otras palabras, se vuelve imposible de perder el objeto del que uno quiere desprenderse, lo que anula, inmediatamente, la capacidad del lenguaje para recobrarlo pertinentemente.

Patricia Venti, otra estudiosa de la obra pizarnikiana, nos habla también de La condesa sangrienta: "utiliza el lenguaje para infringir el funcionamiento de lo simbólico" (Venti, 2008, p. 29) y nos habla del silencio, como Vizcaíno, de lo cual hemos concluido que existen dos tipos: el silencio textual, ya que la economía de Pizarnik en La condesa... lleva constantemente al lector al disfrute inconsciente de autocompletar, y el silencio como la anulación del lenguaje ejecutada por Erzébet, ya que a sus víctimas "le(s) cosía la boca o, contrariamente, le(s) abría la boca y tiraba hasta que los labios se desgarraban" (Pizarnik, 2012, p. 21) y además señala: "Durante sus crisis eróticas, escapaban de sus labios palabras procaces destinadas a las supliciadas. Imprecaciones soeces y gritos de loba eran sus formas expresivas" (ídem, p.18), y de estas imprecaciones y gritos veremos muchas - y ya no señaladas, sino empleadas- en el discurso de $L a$ bucanera de Pernambuco. Erzébet es, por el momento, la descripción de la anulación del lenguaje: se comunica de una forma salvaje. Señala Venti citando a Bachelard (para quien el grito es la antítesis del lenguaje): "El grito es solo un accidente, un tropiezo, un arcaísmo(...) No imita nada”. (Venti, 2008, p. 44)

Señala Negroni que cuando Alejandra Pizarnik redacta en su diario (1966) "Debo ir nada más que hasta el fondo" evidencia la búsqueda de la sensación ya casi imperceptible de lo que producía la palabra en otro tiempo, no así la "relación corroída entre palabra y cosa (m.m.)” (Negroni, 2003, p. 59); además, toca el tema del crimen como modo de expresión. La condesa no habla; sus crímenes hablan por ella o ella los emplea como su lenguaje, como dijera Pizarnik en uno de sus poemas: que se debía hacer el cuerpo del poema con el cuerpo, lo que propone un lenguaje que da paso a la acción, el acto de vivir como un poema, así de elevado. ${ }^{14}$

El dilema está claro. Frente al deterioro de las palabras, Pizarnik renuncia al poema como instancia privilegiada de encuentro e intenta recuperar el sentido desde una gangrena. La condesa sangrienta inaugura la noche de esa fisura, al tiempo que la poesía se desarticula. En este punto, ambas, autora y personaje, proponen lo mismo. Frente a un lenguaje que se revela como expresión errónea (y estéril), el mundo ha de contemplarse a sí mismo y quedar anónimo. El desamparo es total: se abandona el intento de superar la pérdida haciendo carne al verbo, se condena el lenguaje como representación, suciedad, ruido y convención, y el círculo empieza a cerrarse (...). (ibídem, p. 75)

Siendo más precisos: 
En La condesa sangrienta el impulso transgresor marca un corte: el comienzo de una corrupción lingüística que cifra su esperanza, justamente, en el abandono de todo intento de convertirse en resurrección literaria. Al menos, por un tiempo, mientras el lenguaje no atrape al lenguaje en su circularidad, restituyendo el bloqueo. (Ibídem, p. 76)

Pese a que este artículo pretende realizar un descenso hacia el foso donde vemos estallar la pérdida de poder del lenguaje, es pertinente (considerando que se ha tomado el rumbo de una breve cronología) realizar un apunte de Los poseidos entre lilas ${ }^{15}$, la obra teatral de Pizarnik; en esta, la autora sigue incluyendo elementos de su obra poética, pero, además, es, según Negroni, casi al calco, Final de juego de Samuel Beckett. El escenario es como una cárcel (¿la del lenguaje?); las combinaciones de colores, chirriantes (en esto es distinto); y los elementos en escena son extraños (imposibles). Los personajes son Carol, Segismunda, Futerina y Macho; además, está Litwin, la muñeca. Consideramos que todos son caras de Alejandra Pizarnik: Macho y Futerina, los más infantiles, constantemente pedaleando en los triciclos mecanoeróticos e interviniendo disparatadamente; Segismunda, organizadora y generadora de conflicto, siempre disconforme; y Carol es oyente, complaciente y aprendiz, pero al final se transforma en la voz de la conciencia textual, antagonista, mucho más racional.

Este es el último texto no poético que tiene la cualidad de interpretable y aquí aparece, en palabras de Negroni, una marca de la última escritura pizarnikiana: lo obsceno (desarrollado ampliamente por Cristina Piña).

He aquí, una vez más, la insidiosa reflexión sobre la escritura que atraviesa su obra de principio a fin: en el binomio realidad/lenguaje, no hay salida. No queda más alternativa que subvertir ambos términos de la pareja: desconfiar del mundo, que nos llega siempre mediado por "movedizas" y envilecedoras palabras, e ir simultáneamente al encuentro de una palabra desgarrada, alejada de lo falso y lo inhibido, como una forma de escapar a las tergiversaciones, el prejuicio y la mojigatería inscriptos en la materialidad misma del lenguaje. (Negroni, 2003, p. 84)

Concluye, entonces, Negroni que Los poseídos entre lilas reescribe, mientras La condesa sangrienta no (Negroni le llama "refocalizar"); pero ambas, especialmente la segunda, han empezado la muerte del lenguaje como lo conocemos, como la articulación ordenada y significativa que logra el objetivo, conocido por todos, de comunicar. Aún no hemos asistido a su masacre, la que se logrará en La bucanera de Pernambuco, que se constituye de un montón de desechos tan grotescos que el "humor"16 forma parte de ellos. En Los poseídos... aún no se percibe la transgresión absoluta, la violencia en su máxima expresión, pero ya notamos el cambio de tono.

Rastros de Los poseídos... aparecerán en La bucanera de Pernambuco; esta última está constituida por "artículos" de 1970 absolutamente experimentales. 
Pizarnik los llama "retratos de voces": "Quiero que mis portraits des voix tenga argumento o algo que unifique (justifique) los fragmentos..." (Becciu, 2013, p. 962). Las veintitrés entradas muestran a una Pizarnik bastante distinta de la de sus poemas: se ha perdido la coherencia ahora sí por completo. ${ }^{17}$ Sin embargo, sería apropiado aclarar que esta pérdida de coherencia es intencional. No corresponde a un estado psíquico afectado de la autora, sino a que, con premeditación, se quiere manifestar a la paradójica incomunicación a la que nos vemos sometidos desde nuestro más "eficiente" vehículo de comunicación.

Al leer esta obra, pese a nuestras limitaciones, pudimos diferenciar lo siguiente: ${ }^{18}$ juegos con clics y sonidos ("P ffffffff Plop", "Pif und Paf", "Nas Noches", "Mi-rémi-rém-mí-sí-ré-dó-lar...", "Cé Ache”, etc.), juegos lingüísticos de sonido y sentido ("quédate ${ }^{19}$ kioto", "una costumbre aneja y añeja aconseja y aconeja la gratitud en los proemios", "severísima aseveración de la Sanseverina", "Aristarco el Terco", "Hija natural de Ionesco y de la Unesco. Hija artificial de Lupasco", "El loro rió [sic.] hipotéticamente como quien vaca y erra buscando un hipopótamo", "-¿¿Te engripaste? —dijo Agrippa d' Aubigné”, “-Ahora, a esta hora, los coroneles oran en Orán, a la sombra de un orangután —dijo el ciclista etíope o el ciclíope...", "Tanto sacudió el cubilete que todos salieron de sus cubiles y gritaron que la Reina no estaba en sus cabales", etc.) a los que Negroni señala como deformación de recursos poéticos; palabras inventadas ("voluptad", "respodencó", "Lectoto o lecteta”, "aprobamierda”, “dexubre”, "mallarmearme", "supérstito", "morguenática”, "desgansó”, "madruguistas", "tarahumaron", "narracionó”, "delisiada”, "Mutóse”, "chupaglor", "escrushante”, "poligriyo", etc.); lenguaje soez (“¿De súcubo tu culo o tu cubo?”, "dándose culo con culo", "preferís obrar como los mierdas... proferí la proverbial cantilena de los mierdas", “¿por qué te metés ${ }^{20}$ a balconear desde mi cuento, turra con almorranas?", "todo para la teta, nada para la testuz. Más vale pájaro en mano que en culo”, “¡Culos de otrora! ¡Culos de reserva 1492! ¡Culos rayados por los cruzados!", “Por qué no te vas a pirandelear a la cucha de tu hermana?”, etc.); sátira ("-Peresidentes del poker [sic.] pejecutivo de la Res Púbica, nuestro país es homo... // — ¡sexual! — gritaron. // —géneo, burutos", "Coco Panel levantó la mano. // -Pero Panel ¿Otra vez al baño? Ya le dije que en mis cuentos no hay baño”, etc.); y faltas ortográficas (“¿Qé bida!”).

Negroni anota que todo es objeto de parodia y evidencia la mezcla de idiomas: Pizarnik combina sin orden ni concierto el español, inglés ("It's O.K.", "play ping-pong", "Time is Mami", "beri-beri matches. At what flower are you open?", "Yes, Mary Smith. You are so sorry as Norma and he is glad as Aida"), francés ("Est-ce qu'il existe, Tché", "rendez-vous", "dans ma larinx // en disant iiSoirs!! A l'adoré H") e italiano ("Ya que no hay otro modo de raschiare a fin de practicar una incisione en la realidad", "Ahora hay un color incarnato paseándose por su cara", etc.) y el uso e invención de latinismos ("ad pio", "dixit", "In culo volens loquendi chorlitus", "ad patitam"). 
La descripción general del texto es la siguiente: en primer lugar, vemos el PRAEFACIÓN (claramente un prefacio) que inicia con la frase: "Me importa un carajo que aceptes el don de amor de un cuenticón llamado haschich" (Becciu Ed., 2014, p. 94); luego, aparece el primer índice: el ÍNDICE INGENUO (O NO) con la dedicatoria general a las hijas de Loth y cada entrada dedicada por separado (a Lichtenberg, a Harpo Marx, a Kierkegaard, etc.); en la siguiente página, el ÍNDICE PIOLA dedicado a la bija de Fanny Hill, índices falseados en los que los títulos que los componen no corresponden ni al orden ni a la cantidad de entradas asociadas; luego, aparece ACLARACIÓN QUE HAGO PORQUE ME LA PIDIÓ V., que es de lectura obligatoria para la comprensión de las diecinueve entradas de La bucanera...; en ella se nos explica la existencia de diversos personajes que aparecerán en las anécdotas y los diálogos (la Coja Ensimismada, el loro Pericles, Flor de Edipo Chú, Bosta Watson, Betty Laucha Betinotti. Y no se describen otros que también intervienen). Dice Negroni que la función de esta ACLARACIÓN es que el lector no se espante y que se mantenga conectado a la serie de imposibilidades que resultan la mayoría de los textos a los que se enfrentará; efectivamente, esta aclaración es falsamente cooperativa con el lector, ya que las entradas están plagadas de referencias imposibles de reconocer en su totalidad, y con los juegos del lenguaje descritos anteriormente, la lectura se vuelve un reto para el lector que se empeñe, pero un tránsito tedioso para quien no comparta el nivel cultural que manejaba la autora argentina. La penúltima entrada es homónima del texto completo y posee la dedicatoria a Gabrielle D' Estrées y a Severo Sarduy; el último texto es EL PERIPLO DE PERICLES A PAPUASIA O EL PREBISTERIO NO HA PERDIDO NADA DE SU ENCANTO NI EL JARDÍN DE SU ESPLENDOR. ${ }^{21}$ Pensamos que la primera frase del libro ("Me importa un carajo que aceptes el don de amor de un cuenticón llamado haschich") es la respuesta de Pizarnik ante nuestro gesto en señal de pregunta al terminar de leer esta serie de "retratos de voz": su escritura-vida (siguiendo el programa surrealista) es el don de amor del que habla, pero ante la necesaria destrucción del lenguaje por su incapacidad de comunicar lo sublime, no le importa si este texto-escombro es aceptado.

Como Girondo En la masmédula, Pizarnik trabaja aquí sobre la médula de las palabras y, de ese modo, devuelve a la lengua su materialidad problemática y abre cauce a un reservorio de expresiones verbales prohibidas, inaugurando una política insurreccional contra el pacto comunicativo. (Negroni, 2003, p. 95)

La bucanera de Pernambuco es un trabajo barroco, retador, violento y grotesco; sus contenidos son disparatados y nos muestran la crisis del lenguaje ya sin nombrarla exactamente (como se hizo hasta el último poemario), sino más bien generándola. Los otros textos en prosa también tuvieron esta finalidad, 
pero con La bucanera... estamos asistiendo al punto de mayor tensión de este propósito.

Este es el texto al que, desde un inicio debimos avocarnos, pero nos era imposible realizar tal tarea sin describir el resto del proceso creador de Pizarnik, puesto que, como ya se mencionó, este es el momento cumbre de la ruptura de todo lo aceptable o conocido a nivel de las letras hispanas y explicamos este cisma aludiendo a las particularidades de esta obra: "al menos dentro de nuestro panorama literario (...) y prácticamente del internacional (...) nunca hubo textos obscenos firmados por mujeres hasta la aparición de las obras de Pizarnik" (Piña, 2012, p. 28).

(E)n La bucanera de Pernambuco (...), lo obsceno abandona la representación para emerger como lo dicho en el nivel del significante, subvirtiendo el orden simbólico - la lengua, la cultura-, con lo cual la ecuación sexo-muerte se registra en el lenguaje mismo. (Piña, 2012, p. 53)

Para complementar lo anterior, veamos un par de fragmentos del texto específico que nos ocupa:

El correo semental del ojo ajeno; a Culo Pajarero. - Nos está vedado, provecto escriba, contestar al consultor que ostente elementos reñidos con la moral en boga. Cierto, usted no es el único en orinarse en sueños, pero le rogamos pasar por nuestras oficinas a retirar la sábana mojada que nos mandó. No somos "videntes a distancia" (sic); solamente vendemos pajaritos. A prepúcito, la incontinencia del suyo no parece ser obra exclusiva de la Fatalidad. No lea tanto las memorialistas anónimas (princesas rusa, palatina, cochinchinesa, etc.), pioneras de esos trabajos manuales que, si bien le proporcionan "alegrías de colegial" (como reza en su carta), conspiran contra su vejiga, carajo. (Becciu, 2014, p. 102)

O también,

En Jaén, tres cigüeñas duermen con la pata alzada. Cada vez que alguien dice "puta", cambian de pata, en Jaén, en un establo para caballitos de madera. Acércate, lector mío, y mira la bañaderita donde se baña un pajarito a quien una canonesa exhorta:

- No seas hereje, San Vito, como ese rompecabezas que al reconstruirse manifiesta el sobrenombre de Dios.

- Se puede saber cómo lo llaman? — dijo Vito chapaleando como Chaliapín disfrazado de Vito Dumas.

-Lungo. Pero por favor, Vitito, salí del agua, te me vas a engripar, no juegues con la salud. Venga mi Pitito, venga con su negro carrousel en donde lo van a entalcar, a perfumear, y a un montón de cositinas más. 
- Soy el hijo de sheik -dijo Vitito.

-Y glob — dijo un urutaú.

-Y pif - dijo sin su gorra el gorrión.

- Y paf — dijo un jugador de ludo totalmente ajeno a nuestro texto.

—Córrase, diga —dijo lacanón.

Y Vitito:

- ¿No ves que te confundiste de cuento? ¿Por qué no te vas a pirandelear a la cucha de tu hermana? (Idem, p. 104)

Queremos incidir en lo último de la obra de Pizarnik (La bucanera de Pernambuco), pues en ella la imaginación rompe con la sintaxis, la formación de palabras y la semántica; lo que altera la construcción normal de un texto; es decir, el caos que hemos venido señalando se profundiza, y no se manifiesta en uno o varios personajes (la obra cuenta con muchos diálogos, magnífica manera de crear un mundo en el que el lenguaje es completamente diferente del mundo real), sino que ha invadido todo ámbito, tanto así que se transita entre lo obsceno y lo vulgar. No se podría criticar a la argentina por esto: es un campo muy atrayente; además, ¿qué es experimentar? Es rescatar cada frase con sus días y con sus semanas, infundir su soplo a medida que cada palabra haya sido sacrificada en las ceremonias del vivir (Becciu Ed., 2014, p. 315), como citamos anteriormente. Además, señala la autora en sus Diarios:

4 de octubre(...) Mi proyecto de escribir voces es inteligente, pues denota algún conocimiento de mí. Si tuviera una sola voz no escribiría. Pero ¿cuántas voces? ¿Y cómo identificarlas? Podría nombrarlas[,] pero entonces serían personajes. Intercalaría, eso sí, voces de poetas. También imitación de escritores argentinos. (Becciu Ed., 2013, p. 824)

En esta entrada de su diario de 1966, mientras reflexiona sobre el Bosco y el cuadro Extracción de la piedra de la locura, que dará título a uno de sus últimos poemarios, alude ya a la aglutinación de voces de la que seremos testigos en $L a$ bucanera de Pernambuco.

Podemos, además, tentar una explicación humilde al hecho de que los últimos textos de nuestra escritora hayan sido tan obstruyentes: según el mito decimonónico, la narrativa rebajaba al arte a brindar "simple información circunstancial”; por ende, Alejandra Pizarnik, contra toda convención, aplicó procedimientos como la escritura automática, el azar objetivo o el efecto de destrucción mallarmeano para dotar a su prosa de las cualidades que tienen las formas sublimes y que el lenguaje en general nunca debió perder.

Que Pizarnik se haya dedicado a explorar varios géneros y especies literarias se nos presenta como excusa para, desde todos los campos, poder denunciar que el lenguaje no dice lo que quiere decir, que las palabras han perdido 
su capacidad expresiva y que todos debemos ser conscientes de esto. En otros tiempos, la palabra empeñada era el máximo contrato entre dos personas o entre una persona y su comunidad; Pizarnik niega este poder: rompe el pacto de la palabra y el objeto, o la palabra y la acción, con lo que nos deja completamente huérfanos de orden u honor. Su propuesta sobre el lenguaje nos somete al caos social, institucional y personal.

\section{Conclusiones}

la escritura de Alejandra Pizarnik atravesó dos etapas muy marcadas, ligadas a los momentos de su vida. Primero, mientras fue una joven adulta, con sus primeras publicaciones, existe aún una fe en las posibilidades del lenguaje. La expresión era pulcra y pulida por el deseo de ser una buena poeta. Abundaban los lugares comunes: la infancia, la muerte, la soledad, el silencio, la autoafirmación; a partir de 1968, con el poemario Extracción de la piedra de la locura, el tema del lenguaje se ha vuelto una presencia muy tangible que estalla, aún en el plano poético, en 1971 con El infierno musical. La segunda etapa (la no poética y ligada a sus años finales) se abre con Los poseídos entre lilas, su única obra de teatro (1969), en la que los diálogos torcidos y el ambiente asfixiante en que los personajes se desenvuelven alude a la cárcel en la que se ha convertido la expresión. La explosión de esta es La bucanera de Pernambuco, que, con juegos, incoherencias, mezclas y personajes imposibles reta al lector a continuar adelante mientras se desarrolla el caos que son el PRAEFACIÓN, los índices, la ACLARACIÓN y las diecinueve entradas que la conforman.

El problema del lenguaje siempre ocupó a Alejandra Pizarnik; sin embargo, al inicio sucedió de forma inconsciente: sus poemas diminutos, hechos de recombinaciones de palabras eran la preocupación de no emplear las palabras precisas, los términos mejores para la comunicación de su mundo interior. Esto fue producido por el quiebre con su arraigo territorial y lingüístico: el ser de familia rusa masacrada por la Segunda Guerra Mundial, judía, con una madre que no hablaba bien el idioma, debiendo usar yiddish en casa y el español en el resto de sus comunicaciones le significó el no poder asentarse ni territorial ni lingüísticamente. Mudarse a París por cuatro años es también la búsqueda de una patria, un cambio de código lo es más, pero la influencia del Surrealismo trunca esta empresa: el lenguaje no puede ser ese refugio o esa patria. Se inicia entonces la denuncia y luego el asesinato del vehículo de comunicación. La muerte lingüística, además, termina en un acto de muerte física.

La ruptura con el lenguaje en La bucanera de Pernambuco se evidencia a nivel fónico al jugar con los sonidos de las palabras transgrediendo formas y significados, o al construir enunciados cacofónicos; a nivel morfológico, se produce al componer, derivar y usar parasíntesis; a nivel semántico, por el uso de parónimos, homónimos, ambigüedades e incoherencias y neologismos; a nivel 
sintáctico, por el uso exagerado de la subordinación y por cumplir con la construcción de una frase nominal o verbal pero haciendo uso de combinaciones categoriales que producen estructuras ilegibles o dificultan la lectura.

La actitud de Pizarnik ante su obra es más académica de lo que se piensa: en primer lugar, sabemos por sus biógrafos (como Cristina Piña) que la argentina era implacable ante el asunto de la corrección, lo que le da un enfoque muy profesional a su trabajo; además, tenía su vida dedicada al acto escritural, ya que no se dedicaba a nada más que ello. A pesar de que el lenguaje literario se compone de estructuras del lenguaje común y considerando que la aplicación del criterio de verdad es un absurdo en el análisis literario — pues en este el código tiene matices (e incluso grados de verdad o falsedad) - el lenguaje debe ser preferido al silencio (que es solo la ausencia de lenguaje) y es acto metalingüístico, ya que mediante él se está haciendo tangible su degradación. El lenguaje es ineficiente, pero, aun así, es el vehículo más eficiente de todos.

\section{Notas}

1 Corresponde a los textos mecanografiados y corregidos que se encontraron en una segunda carpeta luego de la muerte de la autora. Fueron publicados en Textos de sombra y últimos poemas por Sudamericana en 1982. Empleamos Alejandra Pizarnik. Prosa completa de Lumen (2014).

2 "De allí mis deseos de hacer poemas terriblemente exactos a pesar de mi surrealismo innato y de trabajar con elementos de las sombras interiores. Esto es lo que ha caracterizado a mis poemas". (Prosa completa, p. 313).

3 Es apropiada esta consideración sobre su obra debido a que se percibe constantemente en ella un empequeñecimiento del hombre ante la vida, una visión pesimista del hombre respecto de su papel en el universo. "Todos los actos del hombre carecerán de altura; todas sus ideas, de profundidad”, dirá Breton (1924).

4 Bretón nos dirá esto de otra manera: "Quiero que la gente se calle tan pronto deje de sentir" (p. 18); es decir, si un momento es "no sublime", entonces no será necesario seguir hablando y, por ende, será inútil a nivel literario. También dirá: "solamente lo maravilloso es bello" (Manifiestos del surrealismo, p. 23).

5 Piña señala lo siguiente: locura, drogas, soledad última, sexualidad no ortodoxa, rebelión generalizada contra las convenciones y, finalmente, el suicidio.

6 “Trabajar con las palabras o, más específicamente, buscar mis palabras implica una tensión que no existe al pintar”. (Entrevista de Moia a Pizarnik, en Prosa completa, p. 314).

7 "Aun si digo sol y luna y estrella me refiero a cosas que me suceden. / ¿Y qué deseaba yo? / Deseaba un silencio perfecto. / Por eso hablo". "Caminos del espejo” (apartado XIII) (Extracción de la piedra de la locura, en Poesía completa, p. 243).

8 “QQué quieres? Un transcurrir de fiesta delirante, un lenguaje sin límites, un naufragio en tus propias aguas, oh avara". Verso de "Extracción de la piedra de la locura" (del poemario del mismo nombre en Prosa completa, p. 251).

9 Consideramos que Pizarnik se permite la destrucción lingüística por "razones surrealistas"; estas la predisponen a alejarse de la crítica. 
10 En la versión de Poesía completa (2011, pp. 398-400) se encuentra dentro del apartado "Poemas no recogidos en libros" con la siguiente nota a pie de página: Árbol de Fuego, Caracas, diciembre de 1971, y La Gaceta del Fondo de Cultura Económica, México, Nueva Época, n 19, julio de 1972. Esta versión sigue la publicada por La Gaceta del FCE.

11 Cristina Piña lo considera un conjunto de notas o lo señala como una sucesión de estampas; en una edición de la obra de Pizarnik de Visor (1993), se le encuentra en otros poemas; y, en una edición de Lumen (2001), se ubica dentro de ensayos. Alejandra Pizarnik, en una carta a Antonio Fernández Molina lo llama "artículo escrito en 1965 (...) que aparece ahora en forma de librito".

12 Publicado póstumamente (1972) en El deseo de la palabra, pero fechado de 1969.

13 También publicado póstumamente, pues Pizarnik murió en 1972.

14 “-Quisiera encontrar un crimen, cuyo efecto perpetuo actuase aún[sic] cuando yo deje de actuar. // - Realiza entonces el crimen moral al que se llega por escrito". Paratexto de Patricia Venti en La dama de estas ruinas. Extraído de La nueva Justine (Marqués de Sade).

15 Seguiremos viendo el "surrealismo innato" de Pizarnik en su obra dramática. La no intervención del autor (o la casi nula intervención del autor) le permite ser al personaje: le da lo que Bretón llama "gloria". Además, pese a la importancia de Carol y Segismunda, no existe un "héroe que recorre el mundo". Los cinco personajes están encerrados en aquella casa, y no existe un rol principal: el personaje principal no puede describirnos a todos (otro paradigma surrealista).

16 La bucanera de Pernambuco (encontrada en una carpeta llamada "Humor") es crítica, se burla de personajes históricos, intelectuales y políticos; consideramos, entonces, que es más un caso de sátira de que humor en sí mismo. Lo que puede parecer gracioso son los juegos del lenguaje, las palabras deformadas y las inventadas, la alteración de la sintaxis, las situaciones y conversaciones inverosímiles que se suscitan o la puesta en ridículo de personaje conocidos, pero no podemos afirmar que el título de la carpeta en la que se encontraron los textos sea apropiado, y menos para críticos e investigadores de narrativa: es evidente que estas entradas no debieron catalogarse tan despreocupadamente como humor.

17 La misma Negroni (2003) afirma que Pizarnik creó ciertos textos inasimilables.

18 Todos los fragmentos que se usaron para ejemplificar lo hallado se tomaron de La bucanera de Pernambuco o Hilda la Polígrafa en la edición de Lumen (2014) que lleva por título Alejandra Pizarnik. Prosa completa (pp. 91-161). Sin embargo, no se está considerando la lista completa, puesto que es muy extensa de referir: se habría tenido que glosar cada entrada.

19 Pronunciado [ke.dá.te], de acuerdo con el dialecto porteño, dialecto circunstancial para Pizarnik, pues esto no disminuyó su sensación de errancia.

$20 \mathrm{El}$ indicativo del verbo "meter" también pronunciado con el uso porteño, lo que nos lleva a señalar que también existe oralidad en los textos pizarnikianos.

21 Los títulos son muestra suficiente de lo "raros" que resultan los textos de la última etapa de Pizarnik; los que coincidirán, además, con el final de su vida. Nombres como EN ALABAMA DE HERACLÍTORIS, EL PERIPLO DE PERICLES A PAPUASIA, LA PÁJARA EN EL OJO AJENO juegan con sonidos y sentidos: todo es "extraño" (o deberíamos decir "nuevo") en La bucanera de Pernambuco. 


\section{Referencias bibliográficas}

Becciu, A. Ed. (2011). Alejandra Pizarnik. Poesía completa. Buenos Aires: Lumen

— Ed. (2013). Alejandra Pizarnik. Diarios. España: Random House Mondadori.

- Ed. (2014). Alejandra Pizarnik. Prosa completa. Colombia: Lumen.

Breton, A. (2006). Manifiestos del surrealismo (1ª ed.). (A. Bosch, Trad.) La Plata: Terramar.

Fuentes, C. (2007). Mundo gótico. Barcelona: Quarentena ediciones.

Moure, C. (2009). La experiencia desnuda del lenguaje. Cristina Piña (ed.). En la trastienda del lenguaje. Nueve miradas a la escritura de Alejandra Pizarnik. Pittsburgh: IILI, pp. 141-173.

Negroni, M. (2003). El testigo lúcido: la obra de sombra de Alejandra Pizarnik. Rosario: Beatriz Viterbo Editora.

Piña, C. (2012). La palabra obscena. En Limites, diálogos y confrontaciones: leer a Alejandra Pizarnik (pp. 77-88). Buenos Aires: Corregidor.

Pizarnik, A. (2012). La condesa sangrienta. Barcelona: Libros del Zorro Rojo.

Venti, P. (2008) La dama de estas ruinas: un estudio sobre La condesa sangrienta de Alejandra Pizarnik. España: Dedalus.

Vizcaíno, S. (2008). Decir el silencio: aproximación a la poesía de Alejandra Pizarnik. Quito: Ediciones Abya-Yala. 